\title{
Forensic evaluation of pedestrian injuries by FORTIS system and its significance for technical analysis of traffic accidents performed using simulation programs
}

\author{
Radoslav Morochovič ${ }^{1}$, Ján Mandelík ${ }^{2^{*}}$, Aleš Vémola ${ }^{3}$ and Alena Obrátilová ${ }^{4}$
}

\begin{abstract}
Background: Currently, simulation programs are used for a technical analysis of accidents including pedestrians as they provide a great amount of data on the physical parameters of the pedestrian's body movement and its contacts with the vehicle or the road. In order to be able to make use of the presented options, it is necessary to obtain additional information about detected injuries from forensic doctors in a way utilizable for technical experts.

Methods: This study includes the results of 250 traffic accidents and approximately 200 real accidents, as well as 255 simulations. The evaluations were based on the investigation of circumstances, accompanying documentation, autopsy findings, photo documentation, and the results of additional expert examinations. We further proceeded in line with the complete autopsy findings in accordance with the requirements of the international classification of diseases.

Results: Previous practice has shown that the modified forensic system FORTIS, due to its capability to parametrize through localization using the PC Fortis @ program, is an important tool to supplement verbal descriptions and localizations of injuries that have been used so far.

Conclusions: The FORTIS system is a usable and universal means of supplementing verbal medical descriptions for the needs of traffic accident analysts with a scoring system of a high informative value. This, in combination with a video simulation of contacts with a pedestrian's body during a collision and with values of physical parameters from simulation programs, makes it possible to significantly increase the value of evidence for the needs of the police and courts.
\end{abstract}

Keywords: Forensic parametrization of injury, Pedestrian, Collision simulation, PC crash

\section{Background}

The development of motorization on roads generally brings not only numerous advantages, but it also has its negatives. According to several estimates, there is about one billion vehicles in use worldwide. This definitely takes

\footnotetext{
*Correspondence: emg@dodo.sk

${ }^{2}$ Department of Transport Safety, University of Security Management, Kosice, Slovak Republic

Full list of author information is available at the end of the article
}

its toll on mankind, namely approximately 300000 dead and 20000000 injured (Moser et al., 1999) in traffic accidents. It is not possible to solve the problem of accident and death rate without a complex analysis of all traffic accident aspects, including the assessment of the extent and type of injuries caused by traffic accidents.

The forensic medicine methods have a long tradition in the field of describing injuries to killed and injured persons and, in fact, no significant change thereof has occurred for a long time. It is obvious that pedestrian 
injuries are caused by the force of a vehicle affecting the body of a pedestrian during a collision, whereas the force (harmful forces, acceleration, etc.) has its particular direction, magnitude and time, and is the result of a contact with the contact surface of the vehicle or the road. The specific force values are reflected in the occurrence of corresponding injuries.

Currently, a technical expert may use simulation programs to analyze the course of an accident, which are a standard tool used for the purpose. The PC Crash program which allows the detection and control of data, such as the location and intensity of contacts with every part of the pedestrian's body after a collision with a vehicle during its subsequent movement and contacts with the vehicle (Moser et al., 1999; Mandelík, 2006; Bobrov et al., 2017), is a typical representative of simulation programs. The possibility to obtain such detailed physical data from the calculation performed allows us to use them to verify the performed calculations of the pedestrian and vehicle collision by comparing the detected pedestrian injuries. The importance of this issue is clear, as in practice there are often significant differences among technical experts regarding the correctness of performed simulations, and thus the conclusions of the expert investigation.

To improve the situation, forensic medicine responded to the use of simulation programs by supplementing a verbal description of injuries with the information about the type and extent of injuries by means of their numerical parametrization, as well as determining the location of the harmful force using the FORTIS system (Mandelík, 2006; Bobrov et al., 2017).

The Department of Forensic Medicine of the Faculty of Medicine of Pavol Jozef Šafárik University in Košice has been dealing with this issue for a long time. The results of 250 traffic accident cases and 200 real accident cases including a pedestrian-vehicle collision were used in the research, as these represent a sufficiently large group of accidents. A comparison with the already existing classic method of parameter evaluation-AIS/ISS (Abbreviated Injury Scale/Injury Severity Score, hereinafter AIS/ ISS) (Mandelík, 2006; Bobrov et al., 2017; TERESIŃSKI \& MĄDRO, 2001) was used. Calculations using simulation programs, as well as video recordings of traffic accidents, have been implemented, which resulted in detailed findings about the course of accidents.

To further investigate the possibilities of using parametrization and localization of injuries in practice, the "Theory of injury and contact signatures" developed by forensic engineers in cooperation with the Department of Forensic Medicine of the Faculty of Medicine of Pavol Jozef Šafárik University in recent years has been used based on a theoretical assessment of 255 simulated pedestrian-vehicle collisions evaluated by means of a neural network (MANDELÍK \& BUNDZEL, 2019; Mandelík et al., 2019).

The result of the whole research is that the FORTIS system, as well as the "Theory of injury and contact signatures," recognized by the police and the courts as a legitimate means of evidence and, based on its use, dozens of criminal cases in the field of traffic accidents have been proven and decided, which significantly accelerated the standard procedures in this area of law (Reitšpís et al., 2013; Cheng et al., 2020).

\section{Methods}

The input data for the assessed cases of fatal pedestrian injuries were prepared based on the analysis of a retrospective file (processing the data from autopsy protocols, investigated circumstances, schemes, and photographs). A 3D Static Strength Prediction Program - 3DSSPP (University of Michigan, USA, freeware) was used as an auxiliary graphic software to visualize contacts on the body surface. The intensity of contacts in Fortis points (FP) is derived from the forensic assessment of the extent and characteristics of the detected injury caused by the contact marked on the body surface. The PC FORTIS (c) program has been developed for this procedure (Fig. 1).

For each case, complete autopsy in accordance with the requirements of the international classification of diseases (10th revision) (World Health Organization, 1994; Sharma et al., 2005) was performed, namely immediate cause of death, basic damage to health, complications, and additional findings. Our own contribution was the division of complications into two groups: direct posttraumatic complications and associated complications, which gave us an opportunity to indirectly evaluate the quality of the provided health care in case the injured person survived.

\section{AIS/ISS injury severity scoring methodology}

The AIS/ISS injury scale is currently considered to be the classic method of assessing injury parameters from the medical point of view. This parametrization is based on a medical assessment of the extent and type of injuries without considering the degree of force required to cause it. The others include GSI (Gadd Severity Index), HIC (Head Injury Criteria), 3MS, TTI (Thoracic Trauma Index), VC (soft tissue injury parameter), and EIC (Extended Injury Parameter), which, however, do not provide a universal information tool for the whole body of the injured person or all types of injuries, which is a condition the FORTIS system methodology fully complies with. Using our own modified FORTIS system, each case was evaluated as a whole. Subsequently, each relevant item of the autopsy findings was evaluated in a similar way. 


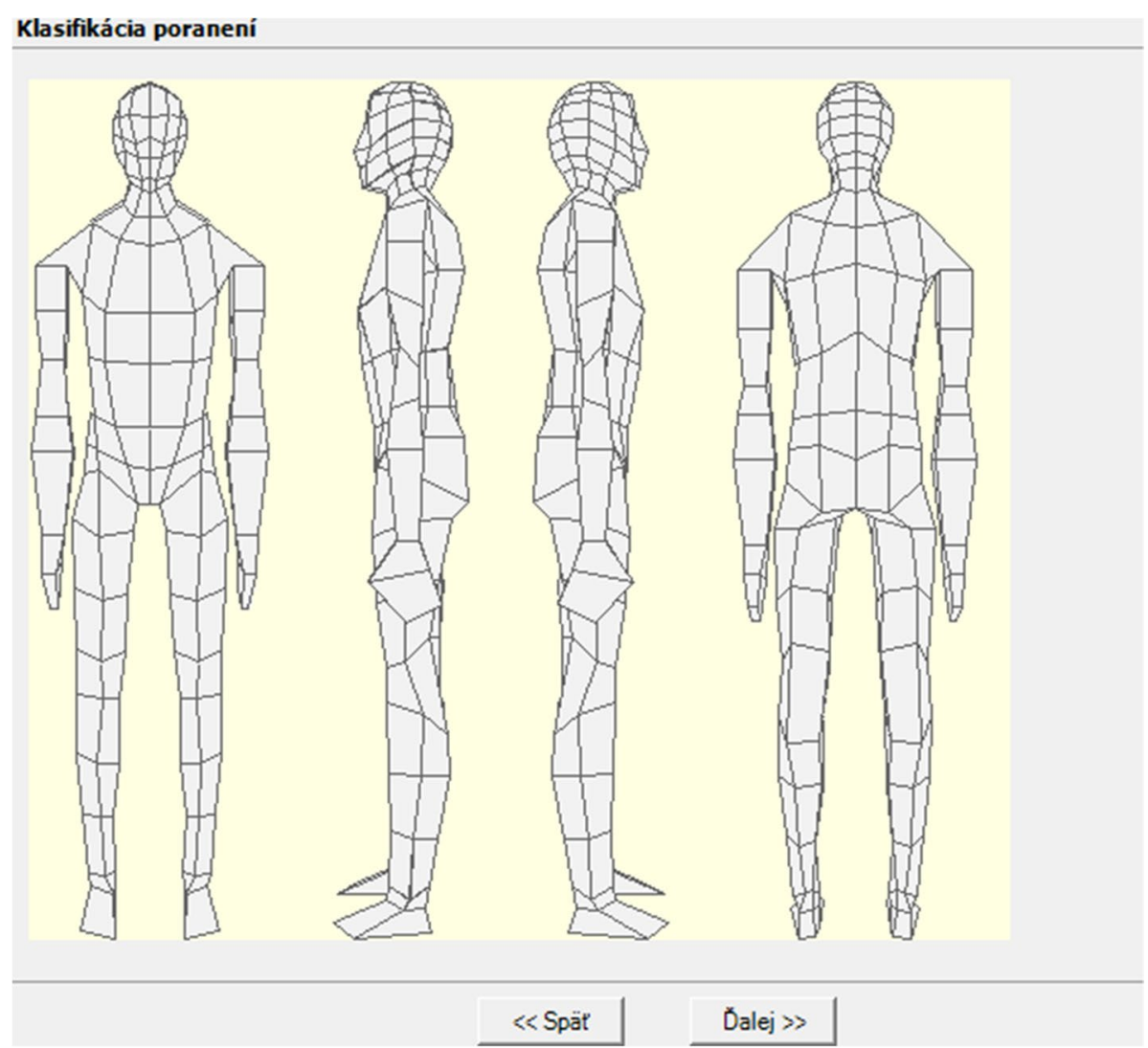

Fig. 1 View of templates to indicate harmful contacts in the PC FORTIS ๑ program

Currently, a forensic analysis of injuries (especially traffic accident injuries) is not always performed in a standard way, primarily due to the lack of an established and precisely specified procedure for the injury parameter standardization. The proposed procedure for assessing traffic accidents, of which the injury parameter standardization in accordance with the internationally accepted AIS/ISS (Abbreviated Injury Scale/Injury Severity Score) scale is a key element, is as follows:

\section{Materials and methods}

$>$ Investigated circumstances, accompanying documentation, autopsy findings, photo documentation, and results of additional expert examinations of fatal pedestrian injuries

1. Complete autopsy in accordance with the requirements of the international classification of diseases (10th revision)

Injury parameter evaluation using our own modified FORTIS system, comparison of FORTIS values with AIS/ ISS values
We compared the results obtained by the above analysis with the classic method of injury parameter evaluationAIS/ISS (Mandelík, 2006; Bobrov et al., 2017; Teresiński \& Kol, 2019) in order to demonstrate the options of the FORTIS system in the injury parameter quantification, especially in cases of pedestrians surviving traffic accidents, to prepare documents for health insurance companies concerning the health care provision quality, as well as to make a possible prognosis of a post-traumatic condition.

\section{Results}

To achieve expected results from the entire process of proving the course of an accident using the exact data on the participants' injuries, and simulation programs, subsequent forensic, and technical procedures are necessary in terms of interdisciplinary research.

\section{Forensic procedures-determination of places of action of injuring forces contacts and parametrization of injuries} To compare the methods of injury parametrization and evaluate their usability for subsequent technical analyses, a point evaluation of 12 investigated cases of fatal 
pedestrian traffic accidents has been performed and the classic AIS/ISS methodology and our own modified FORTIS system have been used. The results are shown in Table 1. It is undeniable that the possibilities of the injury scoring using the FORTIS system are wider, the system is more flexible and relevantly differentiate a degree of health damage of the injury itself $(\mathrm{BDH}-$ basic damage to health which is a direct consequence of the applied force), direct post-traumatic complications (Co1-e.g., traumatic shock, hemorrhagic shock, cardiac tamponade, hemothorax, pneumothorax) and associated complications (Co2-e.g., inflammatory changes, edema of non-traumatic aetiology, thromboses, conditions after surgery). The $\mathrm{Co} 1$ and $\mathrm{Co} 2$ values do not express forces directly applied on the body of an injured person. Therefore, there are separated from the $\mathrm{BDH}$ value.

The values from the compiled tables modified according to the AIS/ISS scale were used for the injury parametrization.

- Add 1 point to score for bilateral fractures (ruptures), for fractures with ligament tears, and for multiple fractures

- Increase score by 0.5 grade for the damage of accompanying the nerve trunk injuries, lymph nodes, and major lymphatic vessels
The FORTIS system includes a total of 39 tables for the injury parametrization. The methodology of the modified FORTIS injury parametrization system differs from AIS/ISS (Bobrov et al., 2017)

- The score of injuries and their complications according to the modified tables

\section{Injury Score in Forensic Medicine}

-Special score of basic damage to health (BDH)

-The complications are divided into two groups:

(1) Direct post-traumatic complications (Co1)

(2) Associated complications (Co2)

-The score also includes decimal positions.

-The maximum score of the FORTIS system is not limited.

The results show that in case of a fatal injury of a pedestrian, the FORTIS score at the location of a traffic accident is relatively high for the $\mathrm{BDH}$ and $\mathrm{Col}$ items; in case a pedestrian survives a traffic accident, the FORTIS Co2 value gradually increases as findings indicating associated complications increase. The FORTIS $\mathrm{Co} 2$ values may also be evaluated from the perspective of the health care quality. The score of basic damage to health and of direct and associated complications is specific for each type of case.

The methodology of the pedestrian traffic accident injury parameter standardization (injury quantification)

Table 1 FORTIS system (Table 37—values for parametrization of head injuries)

\begin{tabular}{|c|c|c|c|}
\hline Group & Injury type & Description of injury & FORTIS \\
\hline \multirow[t]{4}{*}{ I } & Contusion & Blunt injury to the skin and subcutaneous tissues for each $100 \mathrm{~cm}^{2}$ & 0.3 \\
\hline & Rupture & Blunt injury to the muscle tissues for each $10 \mathrm{~cm}^{2}$ & 0.2 \\
\hline & & Laceration of the muscle tissues for each $10 \mathrm{~cm}^{2}$ & 0.3 \\
\hline & & The skin and subcutaneous tissue, according to extent & $1-2$ \\
\hline \multirow[t]{2}{*}{ II } & Fracture & $\begin{array}{l}\text { Traumatic loss of the teeth (except for dentures), for each tooth, depending on } \\
\text { the degree of damage to tooth socket }\end{array}$ & $0.05-0.1$ \\
\hline & & Nondisplaced fracture of face & $1-2$ \\
\hline \multirow[t]{3}{*}{ III } & Fracture & Rupture of vertebral joint at the C-spine & \\
\hline & Blunt injury & Undisplaced fracture of the cervical vertebra & $2-3$ \\
\hline & & Eye contusion & $2-3$ \\
\hline \multirow[t]{7}{*}{ IV } & Fracture & Nondisplaced fracture of the skull base & $3-4$ \\
\hline & Rupture & Disrupted integrity of meninges & $3-4$ \\
\hline & Blunt injury & Diffuse axonal brain damage (by extent) & $3-5$ \\
\hline & Hematoma & Brain contusion (according to location, extent) & $3-5$ \\
\hline & & Subarachnoid hemorrhage (according to extent) & $2-4$ \\
\hline & & Subdural or intradural hemorrhage & 3 \\
\hline & & + each $50 \mathrm{ml}(50 \mathrm{~g})$ of blood in excess of $100 \mathrm{~g}$ & +1 \\
\hline \multirow[t]{2}{*}{ V } & Devastating damage & Rupture of junctions between individual parts of the brain & 6 \\
\hline & & Extrusion of the brain & 6 \\
\hline
\end{tabular}


Table 2 Pedestrian injury score using the classic AIS/ISS methodology and our own modified FORTIS system

\begin{tabular}{|c|c|c|c|c|c|c|c|c|c|}
\hline Case No. & Name, age & $\mathrm{M} / \mathrm{W}$ & Vehicle & $\begin{array}{l}\text { Survival } \\
\text { period (hour) }\end{array}$ & ISS & FORTIS total & FORTIS BDH & FORTIS Co 1 & FORTIS Co2 \\
\hline 1 & P.U., 41 years & M & Van & 0 & 66 & 44.1 & 22.4 & 11.7 & 13 \\
\hline 2 & M.J., 38 years & M & Vehicle & 0 & 75 & 82.8 & 47.7 & 16.1 & 19 \\
\hline 3 & A.P., 67 years & $\mathrm{F}$ & Vehicle & 0 & 75 & 78.2 & 53.6 & 17.6 & 7 \\
\hline 4 & E.P., 9 y. & M & Vehicle & 0 & 75 & 57.1 & 41.1 & 9 & 7 \\
\hline 5 & P.S., 49 years & $F$ & Truck & 0 & 75 & 66.3 & 65.3 & 1.0 & 0 \\
\hline 6 & A.Č, 80 years & M & Vehicle & 0,8 & 57 & 83.2 & 66.2 & 12 & 5 \\
\hline 7 & J.N., 58 years & M & Vehicle & 2 & 75 & 97.4 & 77.4 & 7.3 & 12.7 \\
\hline 8 & J.B., 57 years & M & Vehicle & 24 & 75 & 99.2 & 60.8 & 20.7 & 17.7 \\
\hline 9 & I.M., 47 years & M & Vehicle & 72 & 75 & 102.7 & 46.9 & 16.1 & 37.7 \\
\hline 10 & Š.Ch., 57 years & M & Truck & 239 & 75 & 59 & 19.1 & 14.5 & 25.4 \\
\hline 11 & F.K., 51 years & M & Vehicle & 288 & 75 & 27 & 9.3 & 7.7 & 10 \\
\hline 12 & M.P., 39 years & M & Vehicle & 291 & 75 & 60.8 & 24.2 & 8.5 & 28.1 \\
\hline
\end{tabular}

requires the application of our own modified FORTIS scoring system, which enables (with quality input parameters) us to calculate the severity of the basic damage to health, direct post-traumatic complications, and associated complications, including more painful treatments and poor health care. Moreover, it allows us to determine the immediate cause of death in case of fatal injuries.

Based on the assessment of injuries using the FORTIS system, these can be divided into minor, moderate, severe, and life-threatening, where the possibility to predict a prognosis of the injured person to a certain extent proves to be significant.

The following are examples of forensic examinations of fatal injuries and comparison of the scores in the FORTIS system with the AIS/ISS scale, as well as the injuries of surviving pedestrians processed in the PC Fortis $\odot$ program and their parametrization and localization of contacts.

\section{A. Case No. 2 in Table 2}

Investigated circumstances: There was a traffic accident on the road between two villages - a collision between a pedestrian and a vehicle (Renault 21) driven by its owner; the pedestrian suffered injuries to which he succumbed at the scene of the accident.

Immediate cause of death: A shock caused by the trauma and bleeding due to a rupture of the protruding aorta and the aortic arch, a rupture of the thoracic spine with a complete spinal cord rupture, injuries to other organs of the thoracic and abdominal cavities, and fractures of the bones of the cranial vault, base, as well as the left foreleg (Fig. 2)

\section{B. Case No. 4 in Table 2}

Investigated circumstances: A vehicle (VW Passat), while passing by a bus standing at the bus stop, caught with its right side a juvenile pedestrian who entered its track from the right side from the front of the bus and caused him the injuries to which he succumbed shortly after the accident.

Immediate cause of death: A rupture of the connection of the medulla oblongata and the pons with a contusion/rupture of the brain and intracranial hemorrhage and shattered fractures of the cranial vault and base (Fig. 3).

\section{EXAMPLE-evaluation of injuries of a surviving pedestrian using the FORTIS system processed in the PC FORTIS $\odot$ program \\ Injured person $\mathrm{C}-23$ years}

- Basic damage to health:

- Impression fracture of the left temporal bone of the skull over the otocranial level with a displacement of fragments into the cranial cavity

- Moderate brain concussion

- Two lacerations and contusions in the occipital area on the left

- Skin abrasion in the chin area

- Complications: Mild cerebral oedema in the area of the impression fracture of the left temporal bone. 


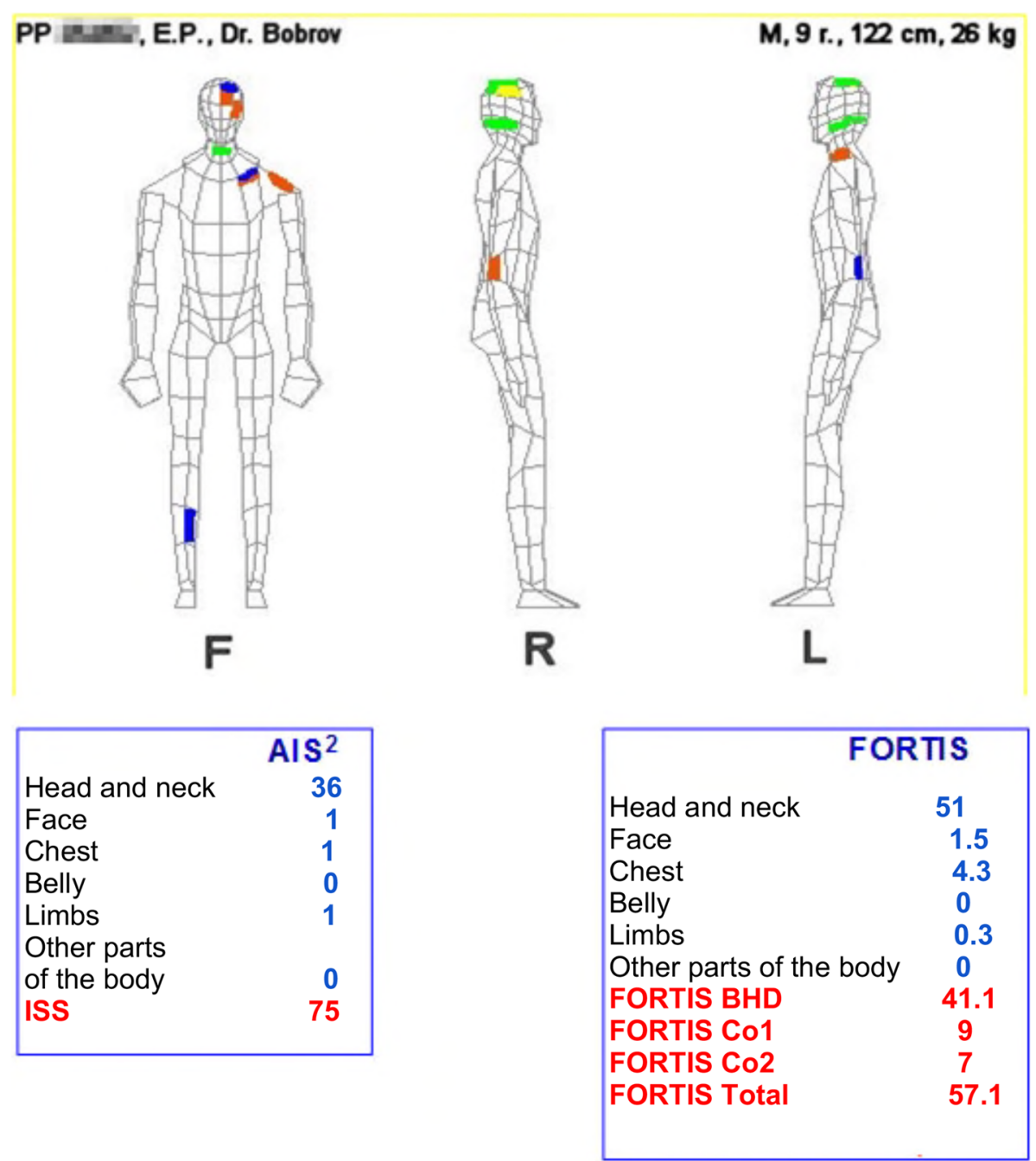

Fig. 2 Evaluation of injury parameters of Case No. 2 using our own modified FORTIS system, comparison of the FORTIS values with the AIS/ISS values

Table 3 Injuries of $C$-23 years are quantified using the FORTIS system

\begin{tabular}{|c|l|c|}
\hline $\begin{array}{c}\text { Serial } \\
\text { No. }\end{array}$ & \multicolumn{1}{|c|}{ Injury description C - 23 y. } & $\begin{array}{c}\text { FORTIS } \\
\text { points of } \\
\text { basic } \\
\text { health } \\
\text { damage } \\
\text { (FP-BHD) }\end{array}$ \\
\hline 1 & $\begin{array}{l}\text { Impression fracture of the left temporal bone of the skull over the } \\
\text { otocranial level with a displacement of fragments into the cranial } \\
\text { cavity }\end{array}$ & 2.7 \\
\hline 2 & Moderate brain concussion & 0.5 \\
\hline 3 & Two lacerations-contusions in the occipital area on the left & 0.3 \\
\hline 4 & Skin abrasion in the area of chin & 0.1 \\
\hline & FORTIS overall pointing score by categories (FP-BHD) & 3.6 \\
\hline
\end{tabular}




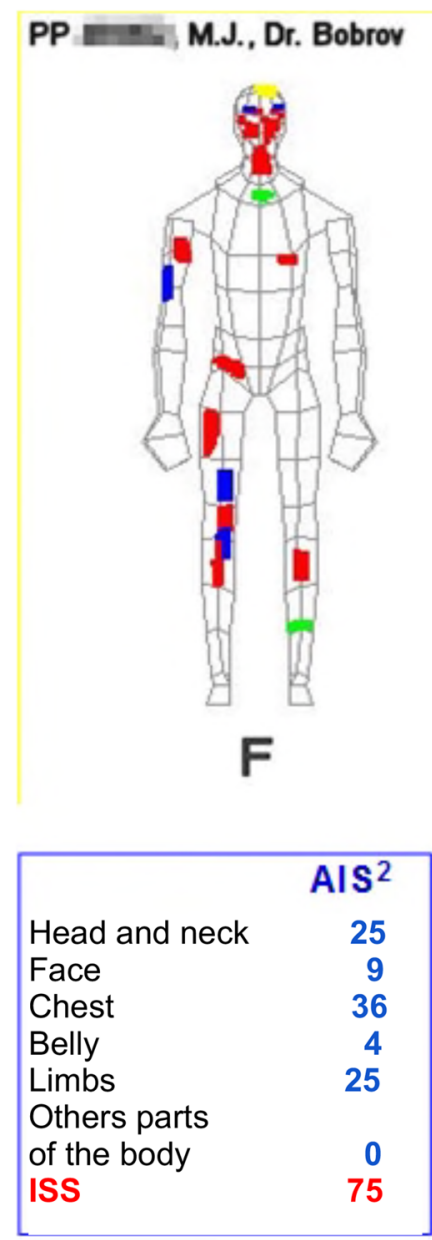

\section{M, 38 r., 185 cm, 80 kg}
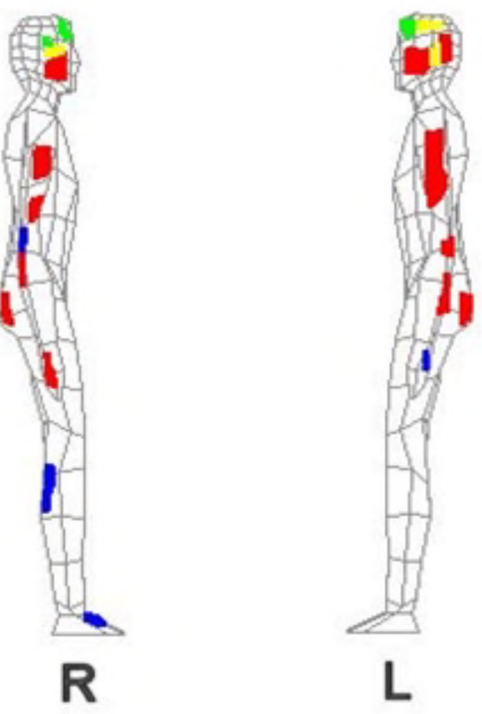

\begin{tabular}{|lr|}
\hline \multicolumn{2}{|c|}{ FORTIS } \\
Head and neck & 22.5 \\
Face & 11.5 \\
Chest & 35.8 \\
Belly & 2.9 \\
Limbs & 6.5 \\
Other parts of the body & 3.6 \\
FORTIS BHD & 47.7 \\
FORTIS Co1 & 16.1 \\
FORTIS Co2 & 19 \\
FORTIS Total & 82.8 \\
& \\
& \\
\hline
\end{tabular}

Fig. 3 Evaluation of injury parameters of Case No. 4 using our own modified FORTIS system, comparison of the FORTIS values with the AIS/ISS values

- Related findings: Condition after a surgical removal of the bone fragments in the area of the impression fracture of the left temporal bone.

\section{- Associated diseases: Unidentified}

\section{- Secondary findings: Unidentified}

The localization of contacts and quantification of injuries of $\mathrm{C}$ were performed using the FORTIS score system (Forensic Traumatology Injury Scale).
The injuries were quantified using the FORTIS score system (Forensic Traumatology Injury Scale), and the harmful contacts were localized (Teresiński \& Kol, 2019) - this is a graphic representation of the localization on a human body template in 128 topographic and anatomic areas. The injury quantification in this case reflects the severity of the injuries caused by the accident depending on mechanical energy which caused the injuries. The FORTIS system is a modification of the internationally recognized injury parameter standardization-AIS/ISS (Abbreviated Injury Scale/Injury Severity Score) and it is the method of parametrization of injuries and their complications caused by mechanical 

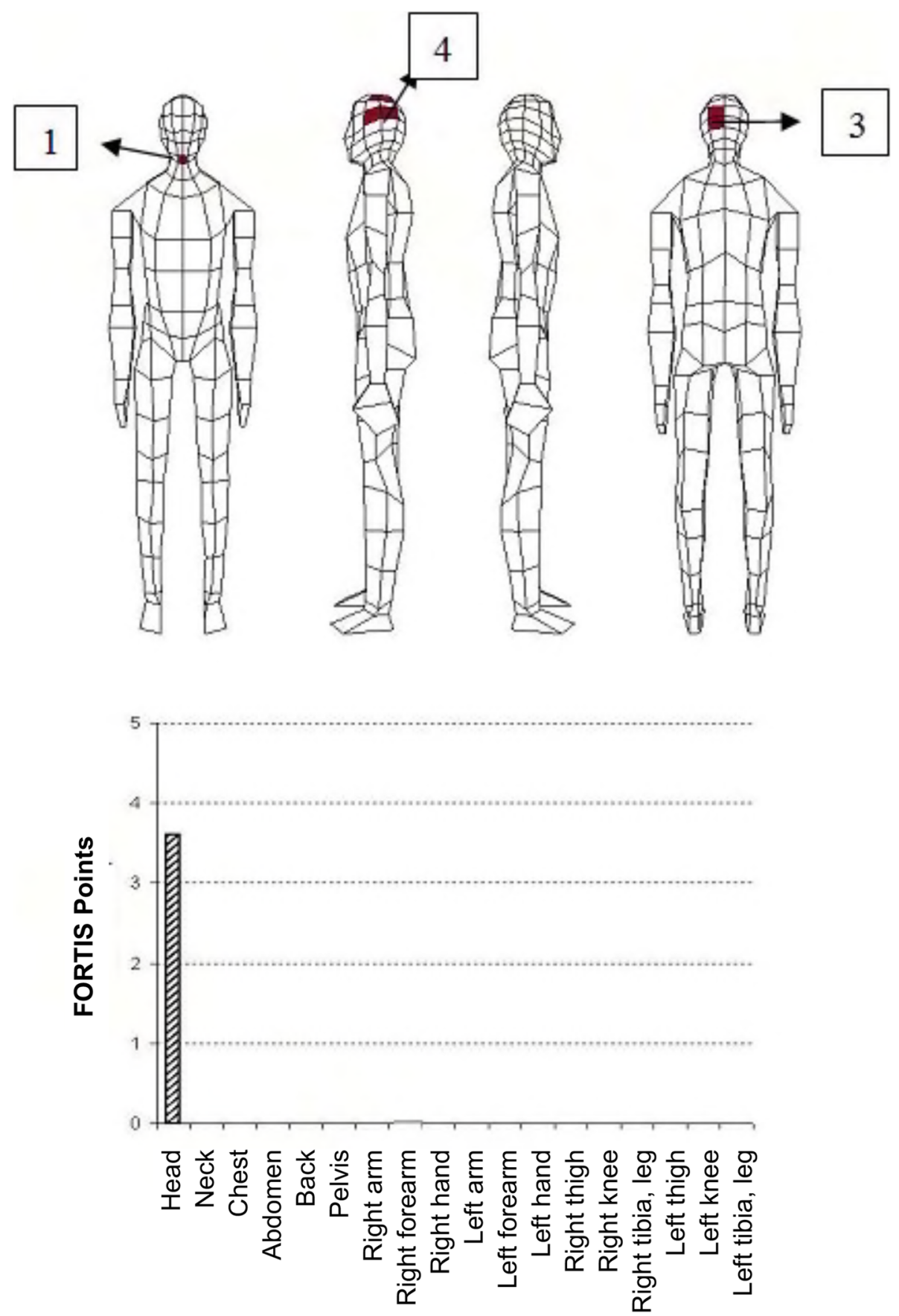

Fig. 4 Localization, quantification, and individual signature of contacts of the injured person C-23 years, detected using the FORTIS score system; the total injury score is 3.6 FORTIS points 
violence (Baker et al., 1984; Bobrov et al., n.d.-b) (Table 3, Fig. 4).

\section{EXAMPLE-evaluation of injuries of a surviving pedestrian using the FORTIS system processed in the PC FORTIS $\odot$ program \\ Injured person $D-47$ years}

- Basic damage to health:

- Comminuted fracture of the lower end of the right radius-extension type

- Fracture of the 1st right splint bone with the luxation of the right hand's thumb-the so-called Rolando fracture

- Fracture of the lateral epicondyle of the right humerus in the elbow joint area

- Complications: Incorrect position of the bone fractures, and slow and painful healing of the lower end of the right radius and 1st splint bone of the right hand.

- Related findings: Condition after a surgical splitting of the fracture of the lower end of the radius with a repeated correction and fixation by means of a reconstructive splint with screws.

- Associated diseases: Chronic bronchitis caused by smoking.

- Secondary findings: Condition after the arthroscopy of the left knee joint in the past (probably due to disease or injury).
The localization and quantification of injuries of $\mathrm{D}$ was performed using the FORTIS score system (Forensic Traumatology Injury Scale) (Table 4, Fig. 5)

\section{E. EXAMPLE-evaluation of injuries of a surviving pedestrian using the FORTIS system processed in the PC FORTIS $\odot$ program \\ Injured person $E-49$ years}

The pedestrian was caught from the front by an oncoming vehicle (Renault Clio) while moving on the road in dark without reflexive gear.

The pedestrian's injuries were quantified, and the contact locations were visualized using the PC FORTIS () program (Table 5, Fig. 6).

\section{Technical procedures-simulations}

Specified contacts - their intensity and localization are defined in a way utilisable in a technical analysis performed using simulation programs (Moser et al., 1999; Mandelík, 2006; Hirt et al., 2011; Vémola, 2009).

The display of selected moments of the simulation from different views (initial and final position, contacts) shows that the localization of contacts is, in addition to determining the contact intensity, a significant tool for correct calculations (MANDELÍK \& BUNDZEL, 2019) (Figs. 7 and 8).

\section{Discussion}

The article aims to introduce and presents the basic starting points and procedures, which include, among others, priority acquaintance with the FORTIS system and its comparison with the now classic existing AIS/ ISS system. From the submitted sample of processed forensic findings, it can be deduced that the Fortis system has a higher informative value with respect to the forensic determination of the physical parameters of the acting violence, which is predominantly mechanical energy. The purpose of this system is not to define

Table 4 Injuries of D-47 years are quantified using the FORTIS system

\begin{tabular}{|c|l|c|}
\hline $\begin{array}{c}\text { Serial } \\
\text { No. }\end{array}$ & \multicolumn{1}{|c|}{ Injury description D - 47 y. } & $\begin{array}{c}\text { FORTIS } \\
\text { points of } \\
\text { basic } \\
\text { health } \\
\text { damage } \\
\text { (FP-BHD) }\end{array}$ \\
\hline 1 & $\begin{array}{l}\text { Comminuted fracture of the lower end of the right radius - extension } \\
\text { type }\end{array}$ & 1.5 \\
\hline 2 & $\begin{array}{l}\text { Fracture of 1. right splint bone with the luxation of the right hand's } \\
\text { thumb - the so-called Rolando fracture }\end{array}$ & 1.0 \\
\hline 3 & $\begin{array}{l}\text { Fracture of the lateral epicondyle of the right humerus in the elbow } \\
\text { joint area }\end{array}$ & 1.2 \\
\hline & \multicolumn{1}{|c|}{ Overall FORTIS score by categories (FP-BHD) } & 3.7 \\
\hline
\end{tabular}



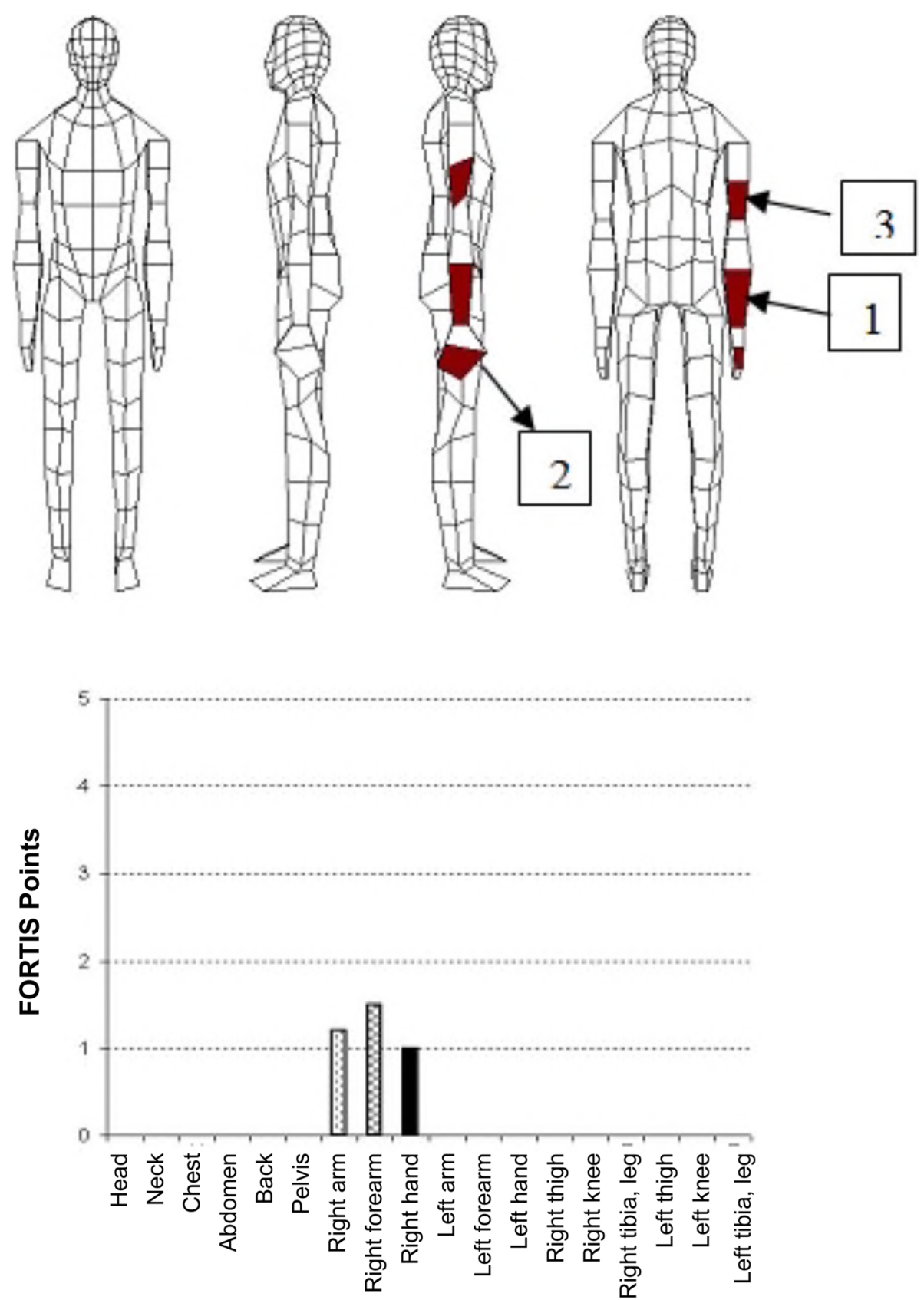

Fig. 5 Localization, quantification and individual signature of contacts of the injured person D - 47 yrs., detected using the FORTIS score system; the total injury score is 3.7 FORTIS points

the degree of damage to the health of the injured person, but it is intended for complex forensic parameterization of detected injuries. For this reason, it distinguishes the primary effect of violence, which represents the value of $\mathrm{BDH}$ from the other identified associated consequences of $\mathrm{Co} 1$ and $\mathrm{Co} 2$.
In the research, the real limitations resulting from the fact that its subject can only be the examination and verification of real cases, where the cooperation not only between forensic doctors and technical experts is needed, but also with the police and other units involved in documenting, investigating, and assessing each case. 
Table 5 Injuries of E-49 years are quantified using the FORTIS system

\begin{tabular}{|c|c|c|}
\hline $\begin{array}{l}\text { Serial } \\
\text { No. }\end{array}$ & Injury description $\mathrm{E}-49 \mathrm{y}$. & $\begin{array}{c}\text { FORTIS } \\
\text { points of } \\
\text { basic } \\
\text { health } \\
\text { damage } \\
\text { (FP-BHD) }\end{array}$ \\
\hline 1 & $\begin{array}{l}\text { Multiple lacerated wounds in the parietal-temporal area of the head on } \\
\text { the left, on the forehead and at the base of the nose }\end{array}$ & 0.7 \\
\hline 2 & Bilateral fractures of the bones of the cranial base and the eye sockets & 5.8 \\
\hline 3 & Fracture of the temporal bone of the skull on the right & 1.8 \\
\hline 4 & Fracture of the jugal bone of the skull on the left & 1.0 \\
\hline 5 & Fracture of the 8 th and 9 th ribs on the right in the back & 1.6 \\
\hline 6 & Fracture of the 7 thrib on the left & 0.8 \\
\hline 7 & Fracture of the body of the 10 th thoracic vertebra & 1.8 \\
\hline 8 & $\begin{array}{l}\text { Breaking off the front part of the } 11 \text { th thoracic vertebra and the } 3 \mathrm{rd} \\
\text { lumbar vertebra }\end{array}$ & 1.8 \\
\hline 9 & Open fracture of the wing of the ilium & 2.0 \\
\hline 10 & Fracture of the beak-shaped protrusion of the scapula on the left & 0.8 \\
\hline 11 & Rupture of the spleen & 3.0 \\
\hline 12 & Contusion and bleeding of the left kidney & 1.6 \\
\hline 13 & $\begin{array}{l}\text { Focal cerebral contusion with cerebral oedema and haemorrhage above } \\
\text { and below the dura mater on the right }\end{array}$ & 4.0 \\
\hline \multirow[t]{2}{*}{14} & Bilateral focal contusion of the lungs & 2.2 \\
\hline & Overall FORTIS score by categories (FP-BHD) & 28.9 \\
\hline
\end{tabular}

Moreover, the limited knowledge of forensic physicians regarding technical simulation programs contributes to their certain misunderstanding of the importance of the FORTIS system for technical analysis as well as for the whole evidence. Therefore, the research is conducted in a long-time horizon, although it represents more than 2000 processed cases to date, a sample of which is presented in this article as examples of forensic processing of findings in terms of parameterization of injuries and visual localization of contacts. Camera recordings that captured the real course of a road accident and the course of contact between a vehicle and a pedestrian (or another participant) proved to be an important tool for verifying the correctness of the performed forensic procedures. It can be stated that forensic medicine and traumatology have not known such system until recently, and its development was limited by the simulation programs used in the technical analysis of traffic accidents; its use contributes to increasing the interdisciplinary approach using new methods applicable to such a procedure.

\section{Recommendations and future directions}

The mentioned FORTIS system has significantly greater possibilities for using it in forensic medicine and traumatology, as it can be gradually utilised not only in the field of road accidents, but in all accident courses (railway accidents, air accidents, violent crimes, etc.). We can assume that it would be appropriate to use the FORTIS system from the first contact 

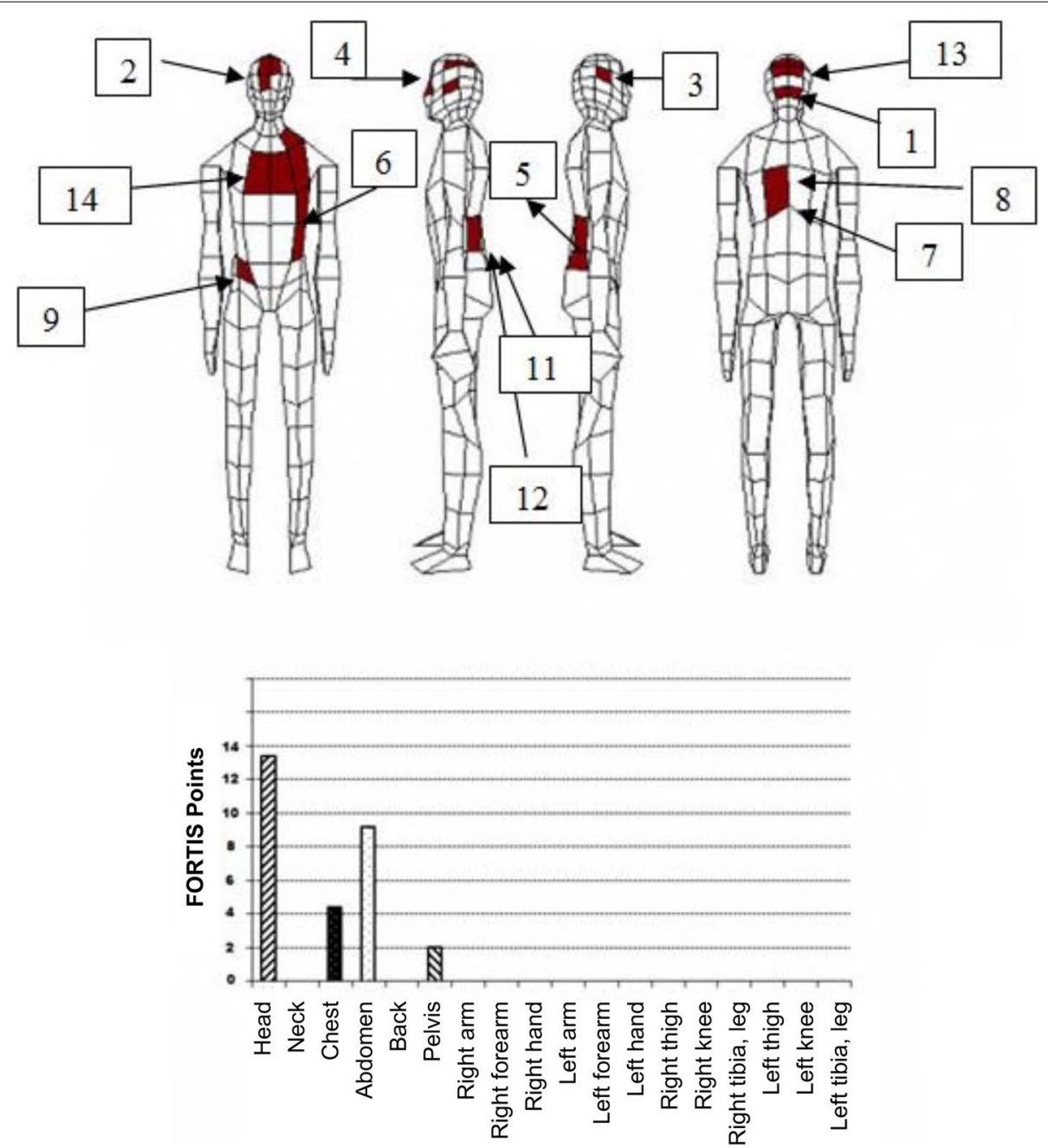

Fig. 6 Localization, quantification, and individual signature of contacts of the injured person E-49 years, detected using the FORTIS score system; the total injury score is 28.9 FORTIS points

between a doctor and a patient who suffered an injury until their recovery. Moreover, it could be implemented in investigating accidents for the legal assessment of all their aspects, for which it provides fully usable information.

To make it more widely used, it is necessary to continue systematic research into the biomechanical properties of the human body, the effects of physical violence on the human body in relation to injuries, and to determine the location and topography of contact points in relation to identified injuries. The method of identifying these places is also important, while it is necessary to carry out all extensive research from the point of view of forensic analysis of accident events.
The mentioned research tasks have been gradually realized in cooperation with the Institute of Forensic Medicine of the Faculty of Medicine and the Department of Trauma Surgery of the P. J. Safarik University in Košice and with experts in technical analysis of traffic accidents who use simulation programs to determine the physical parameters. Another condition for use is the implementation of the presented procedures into the police investigation of traffic accidents, which at present must always have an interdisciplinary character. This means that it uses knowledge from the field of forensic medicine and forensic engineering in order to perform analyses of traffic accidents with high probative value. The authors in their activities, as experts 


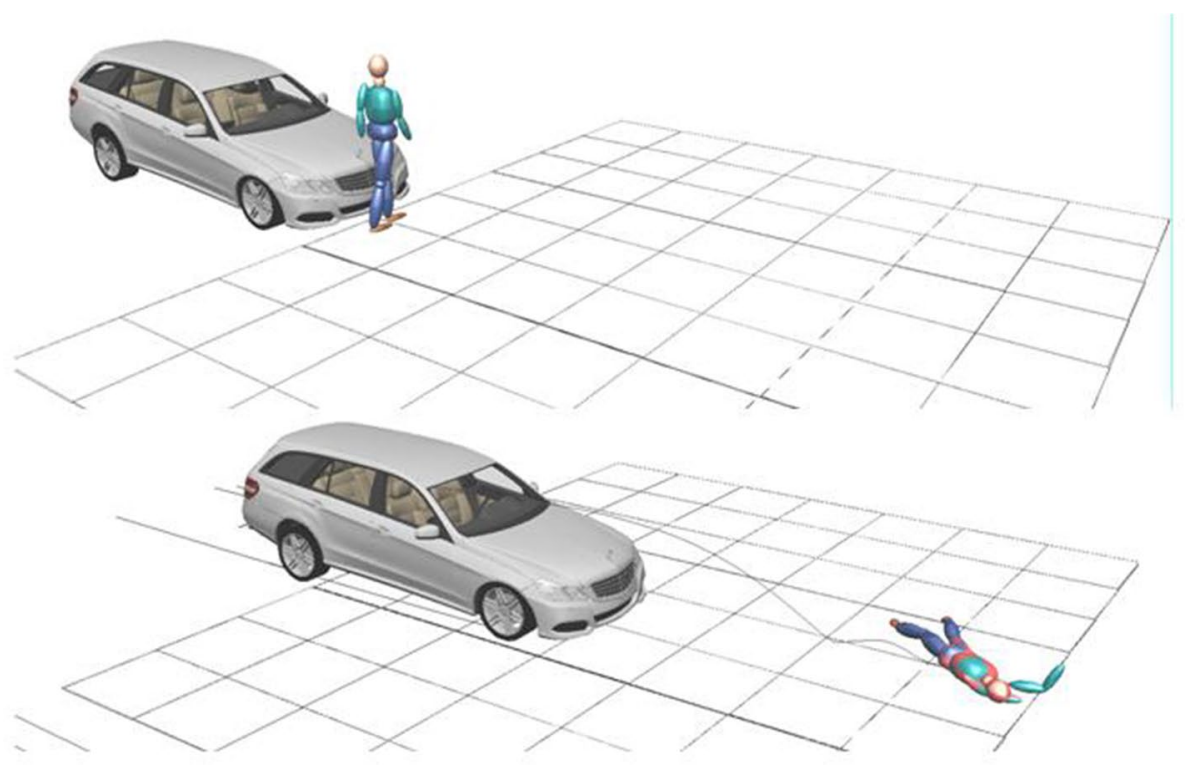

Fig. 7 Initial and final position of the pedestrian and the vehicle - a simulation using PC Crash

cooperating with the police, deal with cases where it is necessary to assess under what circumstances a traffic accident would occur, but also under what circumstances there was no injury to the participants (e. g., the use of seat belts, lower impact speed, safety helmet), thus obtaining and providing information without which, and without the presented procedures and the FORTIS system such cases cannot be solved at present. Undoubtedly, the fact that they have been recognized by the courts in Slovakia as a means of evidence, which is thus binding for the entire European Union, is undoubtedly important for the entire research and the presented procedures.

\section{Conclusions}

The FORTIS system is a practically utilizable universal tool enabling to supplement a verbal description of injuries with a description of injuries expressed in points by means of their parametrization and localization with a high informative value in a form suitable and usable for the needs of experts-traffic accident analysts. It is an advantage that no special medical and anatomical knowledge is necessary for a technical expert to properly understand the presented data. This is important given that the FORTIS system virtually eliminates misinterpretation of forensic information on identified injury characteristics by a technical expert.

The performed injury localization and parametrization by a forensic doctor is a possibility to directly visualize presented injuries as a significant piece of information for road transport experts, who are then able to evaluate such information comprehensively, using the theory of injury and contact signatures [3.16]. One of its advantages is a fact that it enables not only the visualization of injury localization, but also a creation of an individual injury signature (the ratio of forces at the time of injuries on individual body parts according to its division corresponding to a body calculation model-a multibody system in PC Crash) for a specific type of a collision and for specific conditions, including the characteristics of the pedestrian's body, their position, movement, a type of the vehicle, its speed, dynamics at the moment of a collision, and so forth. The following data on the distribution of the energy applied to the pedestrian's body during a collision were obtained and recalculated using the PC Crash program in the conducted research, and it was possible to state that these always have individual features for each collision which can be used to create characteristic signatures (Bobrov et al., 2017; MANDELÍK \& BUNDZEL, 2019; BOBROV et al., 2016; Mandelík et al., 2019; Bobrov et al., n.d.-b).

It is obvious that for the needs of traffic accident analysts in dealing with vehicle-pedestrian collisions there is a possibility to compare the degree of accord of the injury localization in their own calculations and to compare the distribution of the overall energy affecting the pedestrian's body during a collision using a calculation program. 

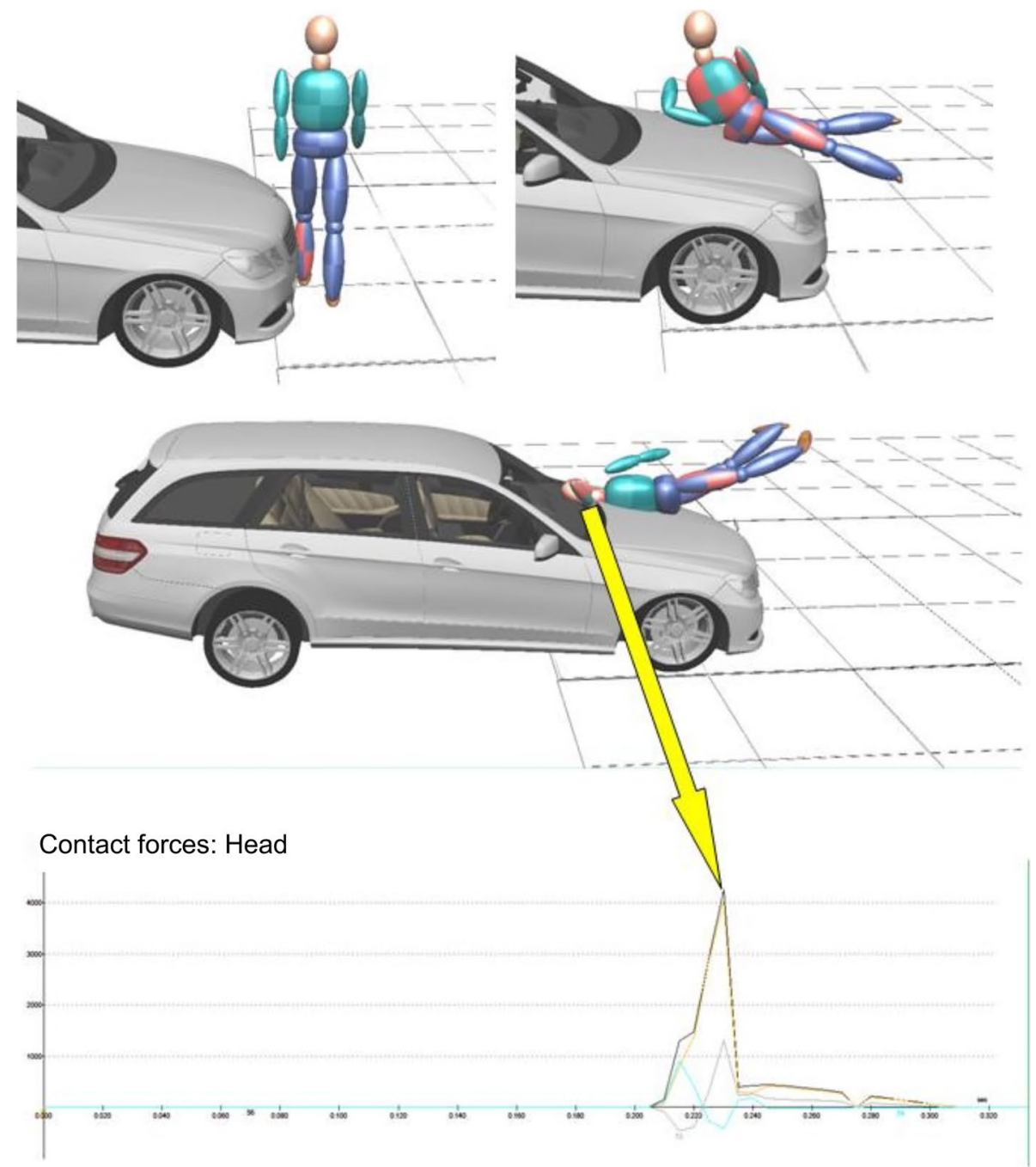

Fig. 8 View of the pedestrian-vehicle contacts and head contact parameters (a simulation using PC Crash), a possibility to identify the localization of the contact and determine its intensity using the contact force time chart

\section{Abbreviations}

FORTIS: Forensic Traumatology Injury Scale; 3DSSPP: 3D Static Strength Prediction Program; AIS: Abbreviated Injury Scale; ISS: Injury Severity Score; GSI: Gadd Severity Index; HIC: Head Injury Criteria; 3MS, TTI: Thoracic Trauma Index; VC: Soft tissue injury parameter; EIC: Extended Injury Parameter; BDH: Basic damage to health; Co1: Post-traumatic complications; Co2: Associated complications; FP: Fortis points.

\section{Acknowledgments}

We thank the staff of the Institute of Forensic Medicine, Faculty of Medicine, University of P.J. Safarika, in Košice for assistance in carrying out the study.

\section{Authors' contributions}

R. M.: participation and performance of medical procedures; J.M., A. V.: participation in the evaluation of diagnoses, simulation modeling of cases, technical assessment, and description of cases. A. O.: text processing and finalization. The authors read and approved the final manuscript.

\section{Funding}

The authors, themselves without any other support, funded the presented research.

\section{Availability of data and materials}

Not applicable

\section{Declarations}

\section{Ethics approval and consent to participate}

Ethical clearance: No special ethics approval is needed, the information shared to the Ethics committee, Faculty of Medicine, P. J. Safarik University in Kosice, Slovak Republic.

This manuscript does not mention or cover any use specific or personal data concerning animals or humans or tissues.

\section{Consent for publication}

The authors of the publication are not in a mutual conflict of interests, and they agree with its publication.

\section{Competing interests}

The authors declare that they have no competing interests. 


\begin{abstract}
Author details
${ }^{1}$ Faculty of Medicine of University Hospital of P. J. Safarik and University Hospital of L. Pasteur, Kosice, Slovak Republic. ${ }^{2}$ Department of Transport Safety, University of Security Management, Kosice, Slovak Republic. ${ }^{3}$ Institute of Forensic Engineering, Brno University of Technology, Brno, Czech Republic. ${ }^{4}$ Institute of Forensic Engineering, Brno University of Technology, Brno, Czech Republic.
\end{abstract}

Received: 1 November 2021 Accepted: 12 January 2022

Published online: 07 February 2022

\title{
References
}

Baker SP, Ginsburg MJ, Li G, O'Neill B (1984) The injury fact book. Oxford University Press, Oxford, $\mathrm{p} 190$

Bobrov N, Mandelík J, Havaj P, Rábek V, Piwowarski J (2016) Possibility of the evaluation of injuries of an unbelted passenger in a vehicle and the need for special procedures while inspecting the site of the accident, security dimensions. Int Natl Stud Krakow 20:132-164. https://doi.org/10.24356/ $\mathrm{SD} / 20 / 7$

Bobrov N, Mandelík J, Havaj (2017) The possibilities of medico-legal evaluation of injuries and its usage in interdisciplinary traffic accident solving. VŠBM Košice 185(21-9):225 (in Slovak)

Bobrov N, Morochovič R, Mandelík J (2019) The FORTIS forensic system and its use in the assessment of traffic accidents, 28th Annual Congress of the European Association for Accident Research and Analysis (EVU). 24-26 October 2019 Publishing, Barcelona

Cheng G, Cheng R, Pei Y, Xu L (2020) Probability of roadside accidents for curved sections on highways. Math Probl Eng:1-18. https://doi.org/10. $1155 / 2629$

Hirt M et al (2011) Tupá poranení v soudním lékařství, (Blunt injuries in Forensic Medicine). Grada Publishing ISBN 978-80-247-4194-9 (in Czech)

Mandelík J (2006) Parametrizácia poranení chodcov a možnosti jej využitia pri riešení nehodového deja (Pedestrian's injuri parametrisation and its usage in description of traffic accidents). University of Žilina: dissertation work (in Slovak)

Mandelík J, Bobrov N, Nevolná Z (2019) Parametrization of pedestrian injuries and its utilisation in proving traffic accidents course using injury signatures and contact signatures. J Biomed Phys Eng elSSN:2251-7200 9(1):3-16

Mandelík J, Bundzel M (2019) Application of neural network in order to recognise individuality of course of vehicle and pedestrian body contacts during accidents. Int J Crashworthiness 24(2). https://doi.org/10.1080/ 13588265.2018 .1432740

Moser A, Steffan H, Kasanický G (1999) Pedestrian model in PC-Crash the introduction of multi body system and its validation. Accident Reconstruction Technology and Animation IX. https://doi.org/10.4271/ 1999-01-0445

Reitšpís J, Gašpierik L, Boc K, FELCAN M. (2013) Policing in the Slovak Republic: the organization and current problems of police work. In: Handbook on Policing in Central and Eastern Europe, pp 239-261

Sharma B, Harish D, Bangar S, SINGH VP. (2005) Trauma score: a valuable tool for documentation of autopsy reports of trauma victims. J Indian Acad Forensic Med 27:77-81

Teresiński G. Kol A. Medycyna sądowa (Forensic Medicine). Warszawa 2019, ISBN 978-83-200-5856-7, p. 1104 (Polish)

Teresiński G, Mądro R (2001) Knee joint injuries as reconstructive factors in carto-pedestrian accidents. Forensic Sci Int 124(1):74-82 (ISSN 0379-0738)

Vémola A (2009) Analysis of traffic accidents with support of simulation programs. J Forensic Engineering 1(p):34-40 ISSN 1211-443X (in Czech)

World Health Organization (1994) 10th revision of the international statistical classification of diseases and related health problems. WHO, Bratislava, pp 1-822

\section{Publisher's Note}

Springer Nature remains neutral with regard to jurisdictional claims in published maps and institutional affiliations.

\section{Submit your manuscript to a SpringerOpen ${ }^{\circ}$ journal and benefit from:}

- Convenient online submission

- Rigorous peer review

- Open access: articles freely available online

- High visibility within the field

- Retaining the copyright to your article

Submit your next manuscript at $\mathbf{s p r i n g e r o p e n . c o m ~}$ 